\title{
Design and Analysis of Sustainable Green Data Center with Hybrid Energy Sources
}

\author{
Akibur Rahaman', Kazi Nusrat Noor ${ }^{2}$, Tanjin Adnan Abir ${ }^{3}$, Sohel Rana', Masum Ali ${ }^{1}$ \\ ${ }^{1}$ Bangladesh University of Business \& Technology (BUBT), Dhaka, Bangladesh \\ ${ }^{2}$ University of Rajshahi, Rajshahi, Bangladesh \\ ${ }^{3}$ American International University-Bangladesh (AIUB), Dhaka, Bangladesh \\ Email: tonmoy17akib@gmail.com, kazinusratnoor@gmail.com, tanjinadnanabir@gmail.com, sohelrana0024bubt@gmail.com, \\ masumali.bubt@gmail.com
}

How to cite this paper: Rahaman, A., Noor, K.N., Abir, T.A., Rana, S. and Ali, M. (2021) Design and Analysis of Sustainable Green Data Center with Hybrid Energy Sources. Journal of Power and Energy Engineering, 9, 76-88.

https://doi.org/10.4236/jpee.2021.97006

Received: November 16, 2020

Accepted: July 27, 2021

Published: July 30, 2021

Copyright $\odot 2021$ by author(s) and Scientific Research Publishing Inc. This work is licensed under the Creative Commons Attribution International License (CC BY 4.0).

http://creativecommons.org/licenses/by/4.0/

\begin{abstract}
Development of renewable energy (RE) and mitigation of carbon dioxide, as the two largest climate action initiatives are the most challenging factors for new generation green data center (GDC). Reduction of conventional electricity consumption as well as cost of electricity (COE) with preferred quality of service $(\mathrm{QOS})$ has been recognized as the interesting research topic in Information and Communication Technology (ICT) sector. Moreover, it becomes challenging to design a large-scale sustainable GDC with standalone RE supply. This paper gives spotlight on hybrid energy supply solution for the GDC to reduce grid electricity usage and minimum net system cost. The proposed framework includes RE source such as solar photovoltaic, wind turbine and non-renewable energy sources as Disel Generator (DG) and Battery. A hybrid optimization model is designed using HOMER software for cost assessment and energy evaluation to validate the effectiveness of the suggested scheme focusing on eco-friendly implication.
\end{abstract}

\section{Keywords}

Green Data Center, Renewable Energy, Sustainability, Hybrid Power Supply, Power Usage Effectiveness

\section{Introduction}

A green data center is typically recognized as facility of a hub of computer system with numerous components, for example, information technology and capacity with most viable energy efficient and tiniest environmental pollution. Generally, it includes redundant records of communication, reserve power sup- 
plies, a number of safety units and environmental controls [1]. Worldwide expenses money on data center power for cooling purposes is approximately 30 billion [2]. Huawei develops green power base station to reduce carbon. Several researches have been shown that data center reaches up roughly 8.6 million which results in enormous electricity consumption and increased carbon into atmosphere [3]. Nowadays, data centers are increasing servers' channel to compensate their servers' request; they commonly participate by means of turning on their backup diesel generator which is neither price effective nor environmentally friendly. For instance, a standby diesel generator frequently generates 50 - 60 times greater nitrogen oxides compared to a conventional electric power plant for every kWh of electricity [4].

As a long term and viable option hybrid energy supply has been developed, authors [5] attempted to minimize the operation cost for base station by developing hybrid solar PV/WT solution. One latest paper [6] has reviewed some techniques to reduce the data energy consumption by dispensing work load in a temperature aware manner. A most suitable energy management approach is proposed to minimize the electricity cost of a base station with RE integration and battery storage, while they only consider a solar model and battery system to startup their project [7]. Hence, to enhance the device performance in terms of overall system quality, we need to utilize both renewable and non-renewable energy with enough quantity of electricity storage components.

We have introduced a new hybrid power generation system (PV/WT/DG) to provide electricity to the green data center by simply varying utilization factor and power usage effectiveness (PUE). Here, PV stands for photovoltaic, WT stands for Wind Turbine. In our study, we have considered solar and wind as our primary and DG as secondary energy source. In order to exploit the uses of maximum wind energy WT plays as a prime energy generator along RE sources. We have used battery bank as incorporated storage device to reinforce the system reliability in case of system failure. To design an energy efficient design architecture DG and storage system are great concern because DG generally emits toxic element concentrated greenhouse gases while large energy storage uplifts the cost of the energy. Now it is a challenge to have a better system to obtain maximum amount of energy with minimum fuel consumption. Our proposed model is designed using hybrid optimization model electric renewable (HOMER) software.

\section{System Model}

\subsection{Architectural Framework}

In our proposed design we have assumed a Green Data Center (GDC) consists of different homogeneous servers. Figure 1 simply demonstrates the hybrid power supply system for the proposed GDC. Here IT equipment (servers of GDC) is considered as DC load and the other equipment such as lights and cooling device are defined as AC load. To provide optimum electricity to the green data 
center for various load, GDC are equipped with different types of renewable and non-renewable hybrid energy sources through conductor. To perform AC-DC conversion of our proposed design a converter (dual mode) is used and vice versa. An energy management unit (EMU) is stated to connect all renewable energy sources and storage devices together. EMU also protects the devices and ensures the better quality of battery bank for charging and non-charging state.

\subsection{Load Distribution Model}

Green data center (Figure 2) generally receives a large number of service requests and a workload distribution server is used to allocate all of the incoming requests to the available and accessible data center. As we know more power consumption is occurred due to the increase of incoming service requests. In our proposed design we have considered a data center with several hundred to thousand of servers with workload distribution server with $\mathrm{T}$ (Working period of time). We can find out total number of incoming server requests by the following equations [8],

$$
N_{r}[t]=\sum_{k=1}^{D} N_{r}[k, t]
$$

$N_{r}[t]$ denotes the number of request to the data center $k$ at time slot $t$. As we know each data center has some constraints to process certain number of requests and we can find it out by the following [9],

$$
\begin{gathered}
0 \leq n_{r}[k, t] \leq n_{s}[k, t] \times q_{r}[k, t] \\
0 \leq n_{s}[k, t] \leq N_{s}[k, t]
\end{gathered}
$$

here, $n_{s}[k, t]$ defines the total number of active server in $k^{\text {th }}$ data center, $q_{r}[k, t]$ denotes the request processing ability per second and $N_{s}[k, t]$ simply defines the maximum number of server in every $k^{\text {th }}$ data center.

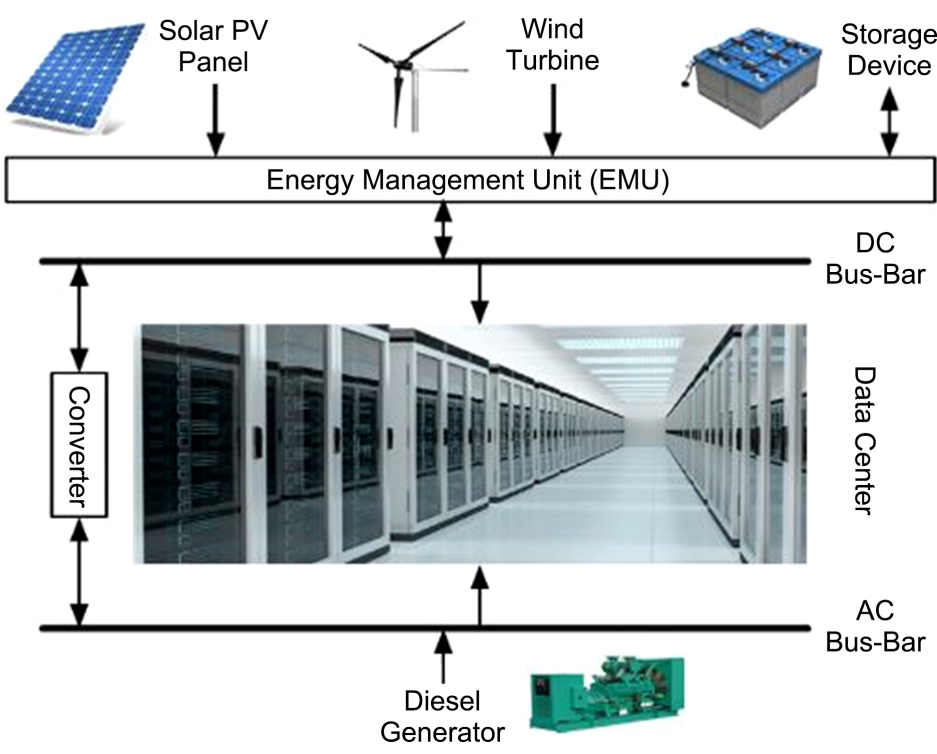

Figure 1. Hybrid PV/WT/DG powered GDC architecture. 


\subsection{Power Model}

The power is consumed in GDC due to the different kinds of IT equipment's such as server and the facility equipment's (cooling and lighting). In GDC the entire server consumes a fixed amount of power in the idle state and it increases with the increase of workload. We can find out the power consumption of a server by the following [10],

$$
\begin{gathered}
Q_{s}=Q_{I}+U_{f} \times\left(Q_{P}-Q_{I}\right) \\
U_{f}[k, t]=\frac{n_{r}[k, t]}{n_{s}[k, t] \times q_{r}[k, t]}
\end{gathered}
$$

here, $Q_{I}$ is the power consumption in idle state, $Q_{p}$ denotes the peak power consumption and $U_{f}$ represents the utilization factor.

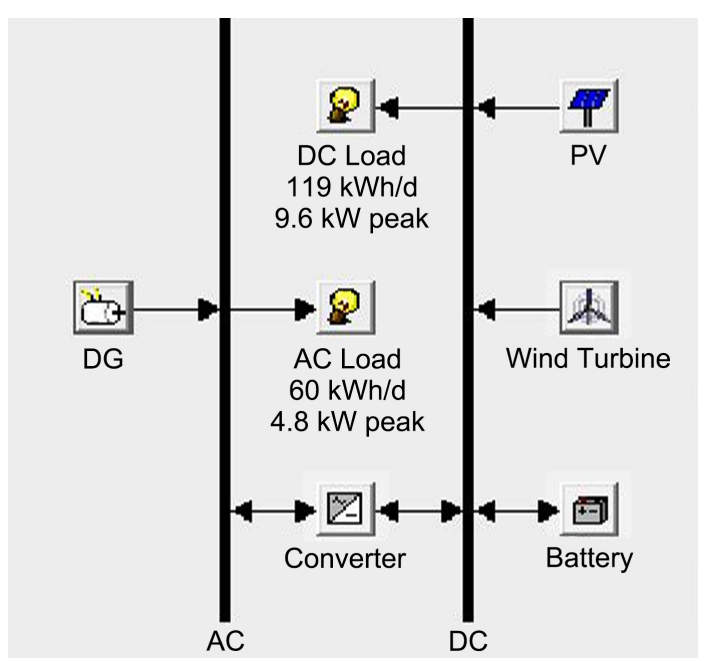

Figure 2. Schematic diagram of the proposed design in HOMER for $N s=1000, \sigma_{\mathrm{PUE}}=1.5$ and $U_{f}=1.0$.

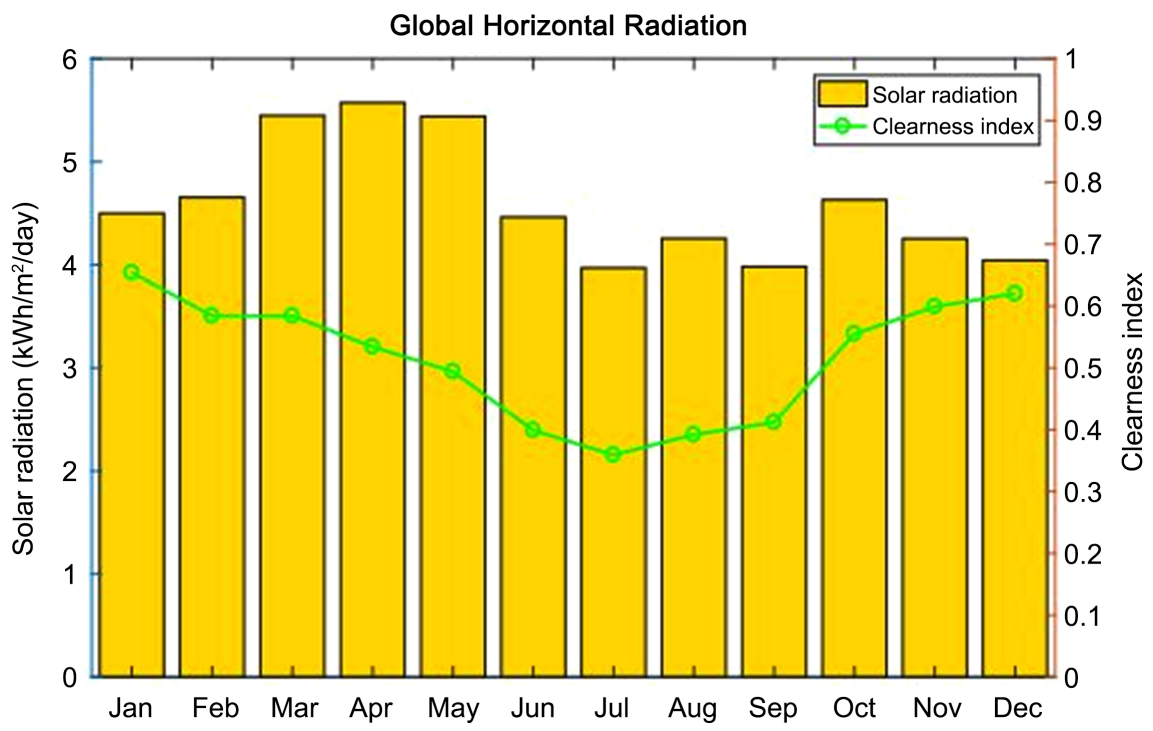

Figure 3. Average annual solar irradiation in Bangladesh. 


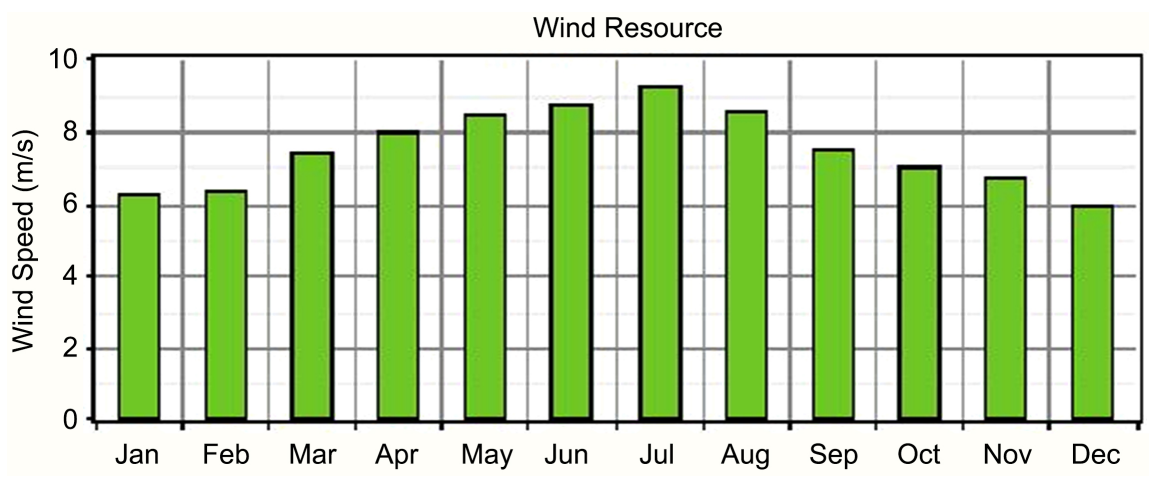

Figure 4. Wind resources profile in Bangladesh.

As we know (Figure 4) that cooling and lightning devices consume power that depends on the power usage effectiveness (PUE). And the optimum value for PUE is considered as 2.0 in several industries. Many researchers use the value of PUE as 1.3, 1.5, and 1.7 and also by the following we can calculate the power consumption of GDC [11],

$$
\begin{aligned}
Q_{D C}[k, t] & =n_{s}[k, t] \times\left[Q_{I}+U_{f}[k, t] \times\left(Q_{P}-Q_{I}\right)\right] \times \sigma_{\mathrm{PUE}} \\
\sigma_{\mathrm{PUE}} & =\frac{\text { Total power comsumption by GDC }}{\text { Total power comsumption by servers }}
\end{aligned}
$$

where, $\sigma_{\mathrm{PUE}}$ denotes as the power usage effectiveness (PUE).

\subsection{Green Energy Model}

As we know (Figure 3) the fact that the nature is unpredictable and the power generation by the solar and wind can varies due to the nature so that the supply of electricity at the GDC sometimes can fluctuate without any prior notification. A diesel generator is used in GDC when the power generations by the renewable sources are insufficient for the GDC. Let consider, $P_{P V}[k, t]$ is power generation from solar source, $P_{W T}[k, t]$ is the power generation from wind turbine and $P_{D G}[k, t]$ denotes the generation from the DG and therefore we can now derive a equation as follows [12],

$$
\begin{array}{r}
P_{D G}[k, t]=Q_{D C}[k, t]-P_{\text {renw }}[k, t] \\
P_{\text {renw }}[k, t]=P_{P V}[k, t]+P_{W T}[k, t]
\end{array}
$$

From above equation it is clear that when $P_{r e n w}[k, t]<Q_{D C}[k, t]$ then $P_{D G}[k, t]$ is positive and it shows the power consumption from DG and for $P_{\text {renw }}[k, t]=Q_{D C}[k, t]$ the value of $P_{D G}[k, t]$ is zero which simply defines that there is no power consumption from DG.

Solar PV Array: As we know that we can get electrical energy from the solar irradiation and it depends on the solar radiation of a particular geographical area. The energy production from the renewable energy source PV can be calculated as following [13], 


$$
E_{P V}=C_{P V} \times \gamma_{r} \times d_{P V} \times \mu \times 365 \text { days } / \mathrm{yr}
$$

Here, $C_{P V}$ is denoted as the capacity of the PV array in $\mathrm{kW}, \gamma_{r}$ is the daily average solar radiation in $\mathrm{kWh} / \mathrm{m}^{2} /$ day, $d_{P V}$ is denoted as the derating factor and $\mu$ is the dual axis tracking factor [14],

Wind Turbine (WT): As we know that wind turbine uses wind to produce energy by the use of turbines mechanical rotation. It transfers the energy to the generator and harvest electrical energy. The production of energy using WT also depends on the geographical area as like PV. The approximate power from the wind is expressed as follows [15],

$$
P_{W T}=\frac{1}{2} \rho v^{3} C_{w t}
$$

Here $C_{w t}$ is the coefficient of the Betz limit and can obtain almost $59 \%$ maximum value for all turbines, $\mathrm{v}$ defines as the wind speed, $\rho$ is denoted the monthly air density $\left(\mathrm{kg} / \mathrm{m}^{3}\right)$.

Energy Storage System (ESS): The series and parallel combination of several batteries is denoted as the Energy Storage System. And ESS is used as a backup energy at the time of impairment of the renewable and non-renewable energy sources. We can calculate the battery autonomy by the following expression [16],

$$
B_{\text {auto }}=\frac{N_{b a t} \times V_{n o} \times A_{n o} \times B_{D O D} \times(24 \mathrm{~h} / \text { day })}{L_{G D C}}
$$

Here, $N_{b a t}$ denotes the total number of batteries, $V_{n o}$ is denoted as the nominal voltage $(\mathrm{V}), A_{n o}$ is denoted as the single battery capacity, $L_{G D C}$ is the daily average load and $B_{D O D}$ is defined as the depth of discharge.

Diesel Generator (DG): We can find out the production of energy from DG by the following expression [17],

$$
E_{D G}=P_{D G} \times \delta_{D G} \times t_{r} \mathrm{kWh}
$$

Here $P_{D G}, \delta_{D G}, t_{r}$ is defines as the rated power output, efficiency of DG and running duration of DG. We also can calculate the diesel consumption by the following expression where $F_{s p}$ is denoted as the specific fuel consumption $(\mathrm{L} / \mathrm{kWh})$ [18],

$$
F_{c}=E_{D G} \times F_{s p}
$$

Here, EDG denotes the specific fuel consumption (L/kWh).

\section{Cost Aware Optimal Framework}

\section{Cost Modeling}

The net percent cost (NPC) denotes the expenditure of the entire lifecycle for our proposed system which includes replacement cost (RC), capital costs (CC), $\mathrm{O} \& \mathrm{M}$ costs (OMC), and also the salvage value $(\mathrm{S})$ within the proposed project lifespan. We can calculate the net percent costs by the following expression [19], 


$$
\mathrm{NPC}=\frac{\mathrm{TAC}}{\mathrm{CRF}}=\mathrm{CC}+\mathrm{RC}+\mathrm{OMC}-\mathrm{S}
$$

Also we can calculate total annualized cost and capital recovery factor by the following [20],

$$
\begin{gathered}
\mathrm{TAC}=\mathrm{TAC}_{\mathrm{CC}}+\mathrm{TAC}_{\mathrm{RC}}+\mathrm{TAC}_{\mathrm{OMC}} \\
\mathrm{CRF}=\frac{i(1+i)^{M}}{(1+i)^{M}-1}
\end{gathered}
$$

Here, $i$ denote the annual real interest rate and $M$ is the project duration. We can also calculate the salvage value of any project lifespan by the following expression [21],

$$
\mathrm{S}=\mathrm{RC}\left(\frac{L_{\text {rem }}}{L_{\text {comp }}}\right)
$$

We have used HOMER software for our optimization because it decides each hour to meet GDC demand at the lower percent cost.

\section{Performance Evaluation}

\subsection{Simulation Setup}

In our proposed design we have used various numbers of homogeneous servers such as $500,100,1500,2000,2500,3000,3500$, and 4000 for our green data center. The power consumption by the each computer server is assumed as $120 \mathrm{~W}$ whereas $60 \%$ power is allocated for the server at its idle state [22]. We also vary utilization factor $\left(U_{f}\right)$ from 0 to 1.0 and $\sigma_{\mathrm{PUE}}=1.3,1.5,1.7,2.0$. The lifespan of our project is considered as 10 years and annual rate of interest is considered as $6.75 \%$ [23]. The simulation setup of PV/WT/DG powered GDC is presented in Table 1.

\subsection{Results Analysis}

We have discussed the energy analysis, optimum size and cost evaluation in this section. HOMER software calculates the energy contribution for various servers for our proposed study in Table 2. Figures 5-8 show the power consumption by the GDC under various system configurations. Here from Figure 5 to Figure 8 we can find the power consumption for our green data center with different servers varying utilization factor and power usage effectiveness. We have calculated different power consumption under the various PUE. All the figures that we have included in this study shows the power consumption by the GDC escalates linearly with the increase of number of servers $\left(N_{s}\right)$, utilization factor $\left(U_{f}\right)$, number of server requests $\left(N_{r}\right)$ and power usage effectiveness $\left(\sigma_{\mathrm{PUE}}\right)$. As we know that larger PUE denotes the high power consumption by cooling, lighting equipment and workload of the server rises with the increment of utilization factor. 
Table 1. Annual energy contribution of different sources.

\begin{tabular}{ccccc}
\hline No of servers & PV (kWh) & WT $(\mathrm{kWh})$ & Dg $(\mathrm{kWh})$ & Total load $(\mathrm{kWh})$ \\
\hline 500 & 3532 & 29,318 & 0 & 32,850 \\
1000 & 15,691 & 43,978 & 6031 & 65,700 \\
1500 & 28,440 & 58,637 & 11,473 & 98,550 \\
2000 & 37,710 & 58,637 & 35,324 & 31,400 \\
2500 & 41,150 & 71,590 & 50,657 & 163,397 \\
3000 & 62,848 & 71,590 & 62,662 & 197,100 \\
3500 & 93,002 & 71,590 & 65,358 & 229,950 \\
4000 & 111,896 & 85,590 & 65,458 & 262,800 \\
\hline
\end{tabular}

Table 2. Simulation setup of PV/WT/DG powered green data center.

\begin{tabular}{|c|c|c|}
\hline System Components & Parameters & Value \\
\hline \multirow{5}{*}{ PV } & Operational Lifetime & 25 years \\
\hline & PV derating factor & 0.9 \\
\hline & Capital cost & $\$ 1 / \mathrm{W}$ \\
\hline & Replacement cost & $\$ 1 / \mathrm{W}$ \\
\hline & $\mathrm{O} \& \mathrm{M}$ cost/year & $\$ 0.01 \mathrm{~W}$ \\
\hline \multirow{6}{*}{ WT } & Size & $3 \mathrm{~kW}$ \\
\hline & Hub height & $50 \mathrm{~m}$ \\
\hline & Operational lifetime & 25 years \\
\hline & Capital cost & $\$ 0.6 / \mathrm{W}$ \\
\hline & Replacement cost & $\$ 0.6 / \mathrm{W}$ \\
\hline & O \& M cost/year & $\$ 0.05 / \mathrm{W}$ \\
\hline \multirow{7}{*}{ Battery } & Round trip efficiency & $85 \%$ \\
\hline & $\mathrm{B}_{\mathrm{SOCmin}}$ & $30 \%$ \\
\hline & $\mathrm{V}_{\text {no }}$ & $6 \mathrm{~V}$ \\
\hline & $\mathrm{A}_{\mathrm{no}}$ & $360 \mathrm{Ah}$ \\
\hline & Capital cost & \$300/unit \\
\hline & Replacement cost & $\$ 300 /$ unit \\
\hline & O \& M cost/year & $\$ 10$ \\
\hline \multirow{5}{*}{ Converter } & Efficiency & $95 \%$ \\
\hline & Operational lifetime & 15 years \\
\hline & Capital cost & $\$ 0.4 / \mathrm{W}$ \\
\hline & Replacement cost & $\$ 0.4 / \mathrm{W}$ \\
\hline & O \& M cost/year & $\$ 0.01 / \mathrm{W}$ \\
\hline \multirow{5}{*}{ Diesel Generator } & Efficiency & $40 \%$ \\
\hline & Operational lifetime & $2500 \mathrm{~h}$ \\
\hline & Capital cost & $\$ 0.66 / \mathrm{W}$ \\
\hline & Replacement cost & $\$ 0.66 / \mathrm{W}$ \\
\hline & $\mathrm{O} \& \mathrm{M}$ cost & $\$ 0.05 / \mathrm{h}$ \\
\hline
\end{tabular}




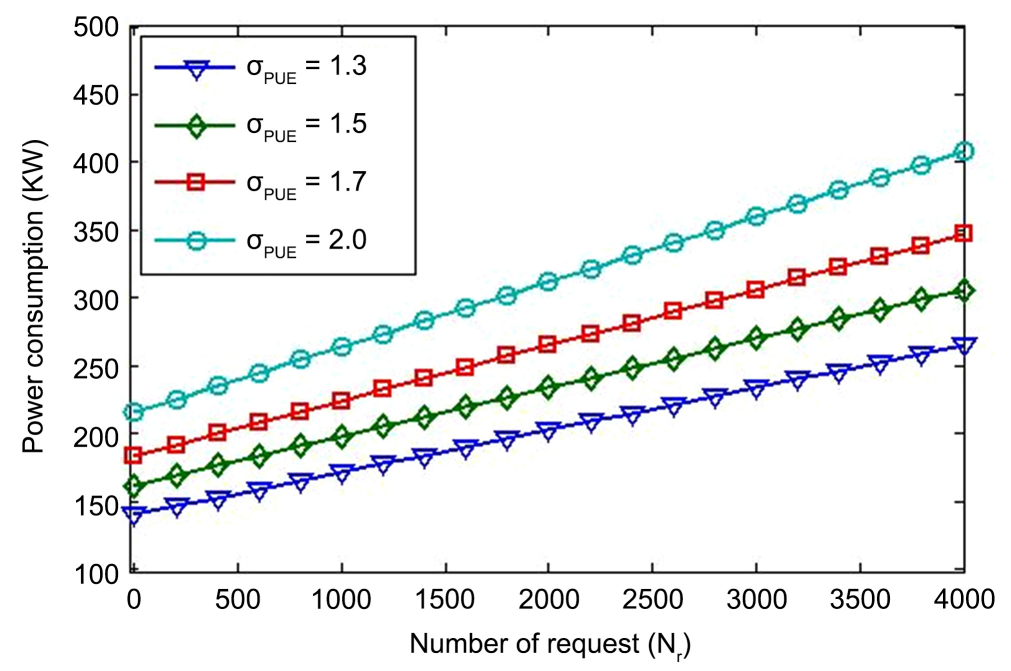

Figure 5. Power consumption vs. $N_{r}$ for $N_{s}=1500$, varying PUE.

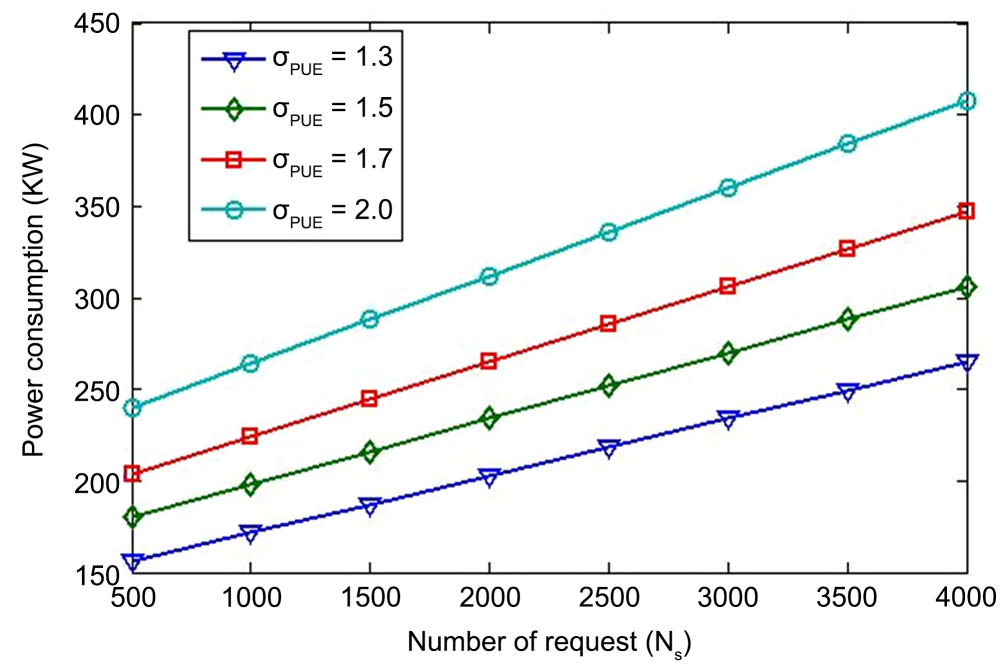

Figure 6. Power consumption for different number of servers varying PUE.

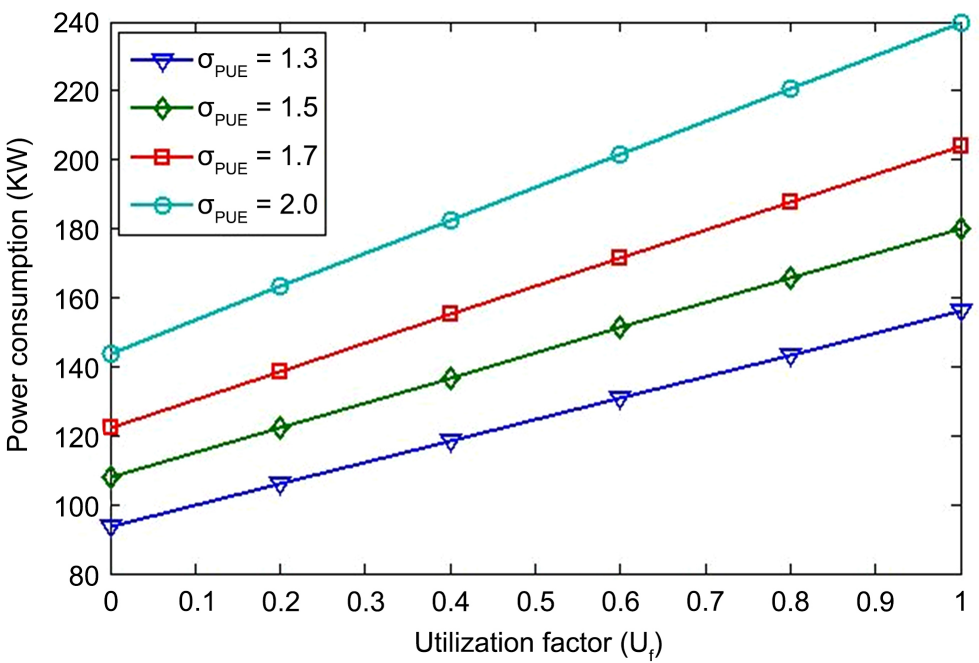

Figure 7. Power consumption vs $N_{r}$ for $N_{s}=1500$, varying $U_{f}$. 
Optimal System Design: We have used the HOMER software for utilizing the design for optimal system configuration which is shown in Table 1. From this table we can see that PV size increases with the increase of large number of servers especially when the number of servers is larger than 1000 . We also can see from the table that The DG size does not significantly change up to 1500 servers but for 3000 to 4000 server's size of the diesel generator changes dramatically and the converter size also changes in the same way.

Energy Yield Analysis. Solar panel for our suggested sharp ND-250QC polycrystalline module with a power of $250 \mathrm{~W}$. Nominal voltage and current for our model is $29.50 \mathrm{~V}$ and $8.50 \mathrm{~A}$. The calculated early electricity providing by the PV source has been estimated by the help of HOMER software. HOMER calculates for energy contribution for $N_{s}=1500, V_{f}=1$ and $\sigma_{\mathrm{PUE}}=1.3$ which is shown in Table 3.

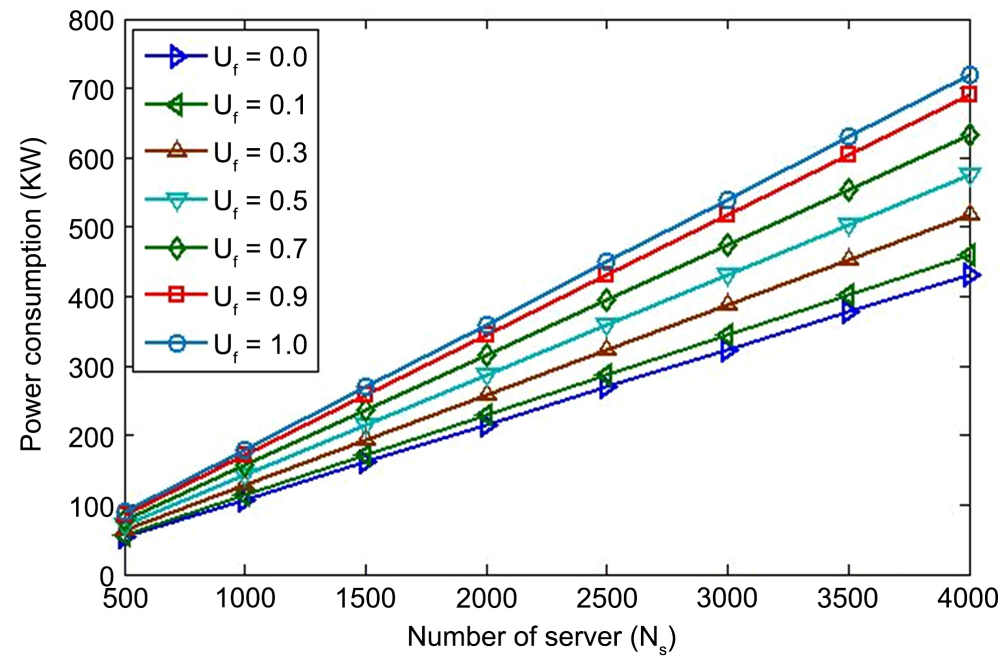

Figure 8. Power consumption vs Utilization factor for $N_{s}=1000$, varying power usage effectiveness.

Table 3. Optimal system architecture for solar radiation of $4.59 \mathrm{kWh} / \mathrm{m}^{2} /$ day for $U_{\mathrm{f}}=1$, $\sigma_{\text {PUE }}=1.5$.

\begin{tabular}{cccccc}
\hline Server & $\mathrm{C}_{\mathrm{pv}}$ & No of $\mathrm{W}_{\mathrm{T}}$ & $\mathrm{P}_{\mathrm{DG}}$ & Battery & Converter \\
\hline 500 & 2 & 2 & 0 & 64 & 2.5 \\
1000 & 8 & 3 & 1 & 64 & 3.5 \\
1500 & 15 & 4 & 2.5 & 64 & 5 \\
2000 & 20 & 4 & 4 & 128 & 7 \\
2500 & 26 & 5 & 5.5 & 128 & 9.5 \\
3000 & 34 & 5 & 6.5 & 256 & 10.15 \\
3500 & 45 & 5 & 8 & 256 & 12 \\
4000 & 56 & 6 & 10 & 256 & 13.5 \\
\hline
\end{tabular}




\section{Conclusions}

Developing the energy cost potency, long term issue and environmental consequences are most concerning factors for the scientist. In this article, associated optimum design of hybrid PV\WT\Diesel power system is self-addressed for GDC. Homer simulation gives the most effective dimension of WT $\backslash P V \backslash D G$ regarding the server utilization issue associated with PUE to create an environment close to realistic situation. Results expose that mounted PV array, WT capacity, and DG power contribution go upward direction with the increment of servers. An overall effect on GDC electricity consumption is discovered for utilization factor $\left(U_{f}\right)$, PUE, and the variation of incoming requests $N_{r}$. Additionally, the battery autonomy is continuously lowering with $N_{s}$. This indicates that the backup hours during hybrid source malfunctions are greater for the decrease quantity of server's capacity. HOMER simulates how the system operates over one year and assumes that the key simulation results for that year (such as fuel consumption, battery throughput, and surplus power production) are representative of every other year in the project.

To put it in a nutshell, this recommended hybrid electricity supply system for larger data center has been demonstrated as a potential solution for off-grid GDC.

\section{Conflicts of Interest}

The authors declare no conflicts of interest regarding the publication of this paper.

\section{References}

[1] Wang, K., Li, H., Feng, Y. and Tian, G. (2017) Big Data Analytics for System Stability Evaluation Strategy in the Energy Internet. IEEE Transactions on Industrial Informatics, 13, 1969-1978. https://doi.org/10.1109/TII.2017.2692775

[2] Jahid, A. and Hossain, M.S. (2018) Intelligent Energy Cooperation Framework for Green Cellular Base Stations. IEEE International Conference on Computer, Communication, Chemical, Material and Electronic Engineering, Rajshahi, 8-9 February 2018, 1-6. https://doi.org/10.1109/IC4ME2.2018.8465490

[3] Jahid, A., Shams, A.B. and Hossain, M.F. (2018) Green Energy Driven Cellular Networks with JT CoMP Technique. Physical Communication, 28, 58-68. https://doi.org/10.1016/j.phycom.2018.03.008

[4] Gu, C., Huang, H. and Jia, X. (2016) Green Scheduling for Cloud Data Centers Using ESDs to Store Renewable Energy. 2016 IEEE International Conference on Communications (ICC), Kuala Lumpur, 23-27 May 2016, 1-7. https://doi.org/10.1109/ICC.2016.7511449

[5] Bagheria, M., Shirzadib, N., Bazdarb, E. and Kennedy, C.A. (2018) Optimal Planning of Hybrid Renewable Energy Infrastructure for Urban Sustainability: Green Vancouver. Renewable and Sustainable Energy Reviews, 95, 254-264. https://doi.org/10.1016/j.rser.2018.07.037

[6] Ghamkhari, M. and Mohsenian-Rad, H. (2012) Optimal Integration of Renewable Energy Resources in Data Centers with Behind-the-Meter Renewable Generator. 
IEEE International Conference on Communications (ICC), Ottawa, 10-15 June 2012, 3340-3344. https://doi.org/10.1109/ICC.2012.6364475

[7] Jahid, A. and Hossain, M.S. (2017) Dimensioning of Zero Grid Electricity Cellular Networking with Solar Powered Off-Grid BS. IEEE International Conference on Electrical \& Electronic Engineering (ICEEE), Rajshahi, December 2017, 1-4. https://doi.org/10.1109/CEEE.2017.8412862

[8] Jahid, A. and Hossain, M.S. (2017) Feasibility Analysis of Solar Powered Base Stations for Sustainable Heterogeneous Networks. IEEE Region 10 Humanitarian Technology Conference (R10-HTC), Dhaka, December 2017, 686-690. https://doi.org/10.1109/R10-HTC.2017.8289051

[9] Nandi, S.K. and Ghosh, H.R. (2009) A Wind-PV-Battery Hybrid Power System at Sitakunda in Bangladesh. Energy Policy, 37, 3659-3664.

https://doi.org/10.1016/j.enpol.2009.04.039

[10] Mondal, M.A.H. and Islam, A.S. (2011) Potential and Viability of Grid-Connected Solar PV System in Bangladesh. Renewable Energy, 36, 1869-1874.

https://doi.org/10.1016/j.renene.2010.11.033

[11] Islam, M.S., Jahid, A., Islam, A.T., Sadath, M.A. and Monju, M.K.H. (2019) Renewable Energy Aware Cost Assessment for Green Data Center with Hybrid Energy Sources. 2019 International Conference on Robotics, Electrical and Signal Processing Techniques (ICREST), Dhaka, 10-12 January 2019, 120-125. https://doi.org/10.1109/ICREST.2019.8644224

[12] Gan, C.K., Prayun, W., Tan, C. and Shamshiri, M. (2014) Design of a Hybrid Diesel/PV/Wind/Battery System in Remote Areas. International Review of Electrical Engineering (IREE), 9, 420-430.

[13] Jahid, A., Islam, M.S., Shams, A.B., Abied, S.R. and Hossain, M.F. (2018) Optimization of Network Sustainability for LTE BS Deployment in Bangladesh with Hybrid Supplies. 2018 4th International Conference on Electrical Engineering and Information \& Communication Technology, Dhaka, 13-15 September 2018, 524-529. https://doi.org/10.1109/CEEICT.2018.8628039

[14] Nayeem, S.M., Yakub, U. and Mostafa, S.G. (2014) Hybrid Renewable Energy System for Sandwip in Bangladesh. 2nd International Conference on Green Energy and Technology, Dhaka, 5-6 September 2014. https://doi.org/10.1109/ICGET.2014.6966676

[15] Rhaman, M.M. (2013) Hybrid Renewable Energy System for Sustainable Future of Bangladesh. International Journal of Renewable Energy Research, 3, 777-780.

[16] Jahid, A., Islam, M.S., Hossain, M.S., Hossain, M.E., Monju, M.K.H. and Hossain, M.F. (2018) Toward Energy Efficiency Aware Renewable Energy Management in Green Cellular Networks with Joint Coordination. IEEE Access, 6, 60900-60920. https://doi.org/10.1109/ACCESS.2019.2920924

[17] Nandi, S.K. and Ghosh, H.R. (2010) Prospect of Wind-PV-Battery Hybrid Power System as an Alternative to Grid Extension in Bangladesh. Energy, 35, 3040-3047. https://doi.org/10.1016/j.energy.2010.03.044

[18] Islam, M.T., Shahir, S.A., Uddin, T.I. and Saifullah, A.Z.A. (2014) Current Energy Scenario and Future Prospect of Renewable Energy in Bangladesh. Renewable and Sustainable Energy Reviews, 39, 1074-1088. https://doi.org/10.1016/j.rser.2014.07.149

[19] Das, H.S., Yatim, A., Tan, C.W. and Lau, K.Y. (2016) Proposition of a PV/Tidal Powered Micro-Hydro and Diesel Hybrid System: A Southern Bangladesh Focus. Renewable and Sustainable Energy Reviews, 53, 1137-1148. 
https://doi.org/10.1016/j.rser.2015.09.038

[20] Han, T. and Ansari, N. (2014) Powering Mobile Networks with Green Energy. IEEE Wireless Communication Magazine, 21, 90-96. https://doi.org/10.1109/MWC.2014.6757901

[21] Han, T. and Ansari, N. (2013) On Optimizing Green Energy Utilization the Cellular Networks with Hybrid Energy Supplies. IEEE Transactions on Wireless Communications, 12, 3872-3882. https://doi.org/10.1109/TCOMM.2013.051313.121249

[22] Chia, Y.K., Sun, S. and Zhang, R. (2014) Energy Cooperation in Cellular Networks with Renewable Powered Base Stations. IEEE Transactions on Wireless Communications, 13, 6996-7010. https://doi.org/10.1109/TWC.2014.2339845

[23] Farooq, M.J., Ghazzai, H., Kadri, A., El Sawy, H. and Alouini, M.-S. (2016) A Hybrid Energy Sharing Framework for Green Cellular Networks. IEEE Transactions on Communications, 65, 918-934. https://doi.org/10.1109/TCOMM.2016.2637917 